\title{
Application of the Iimit equilibrium strength to the seismic assessment of shear related seismicity
}

\author{
J. Jarufe Troncoso Codelco VP Chile, Chile; and The University of Western Australia, Australia \\ Y. Potvin Australian Centre for Geomechanics, The University of Western Australia, Australia
}

J. Wesseloo Australian Centre for Geomechanics, The University of Western Australia, Australia

\section{Abstract}

Over the last several decades, mine-induced seismicity has created serious safety and production issues for underground mines worldwide. A significant proportion of the large seismic events resulting in rockbursts have been related to a 'fault slip' mechanism on shear zones. This source mechanism has been the subject of a number of numerical modelling studies in the past and several techniques have been developed to analyse it, but these methods are highly dependent on the strength properties used to simulate (explicitly or implicitly) the non linear response of the rock mass. A methodology is proposed in this paper to estimate non linear ride without considering explicitly the strength properties of the shear zones, considering the premining Limit Equilibrium Strength (LES). As a result of this methodology, observed seismic trends can be reproduced through numerical modelling and if enough data exists to calibrate the model, accurate magnitudes of seismic moment can be reliably forecasted.

\section{Introduction}

Mine-induced seismicity is a very important issue for deep mining as it has the potential to generate rockbursts and, consequently, damage to equipment, delays in production, and fatalities. In the current mining environment, such consequences are unacceptable and the seismic risk must be mitigated. As seismicity is an inevitable outcome of mining at depth, new mining approaches and sequences need to be assessed using numerical modelling to mitigate against the adverse effects of the induced seismicity.

To properly simulate the seismic response, a good understanding of the failure mechanism is essential. Two broad types of mine tremors are generally distinguished (Ryder, 1988; Gibowicz and Kijko, 1994; Board, 1994; Wiejacz and Lugowski, 1997), one associated with fracturing on the mining face - caused by crushing of highly stressed volumes of rock; and the other associated to displacements on major geological discontinuities related to slip or rupture along planes in the rock mass (Figure 1).

A significant proportion of large seismic events results from shearing mechanisms (Ortlepp, 1997). For this reason, the quantification of shear on known fault planes has received attention from researchers in the past. 


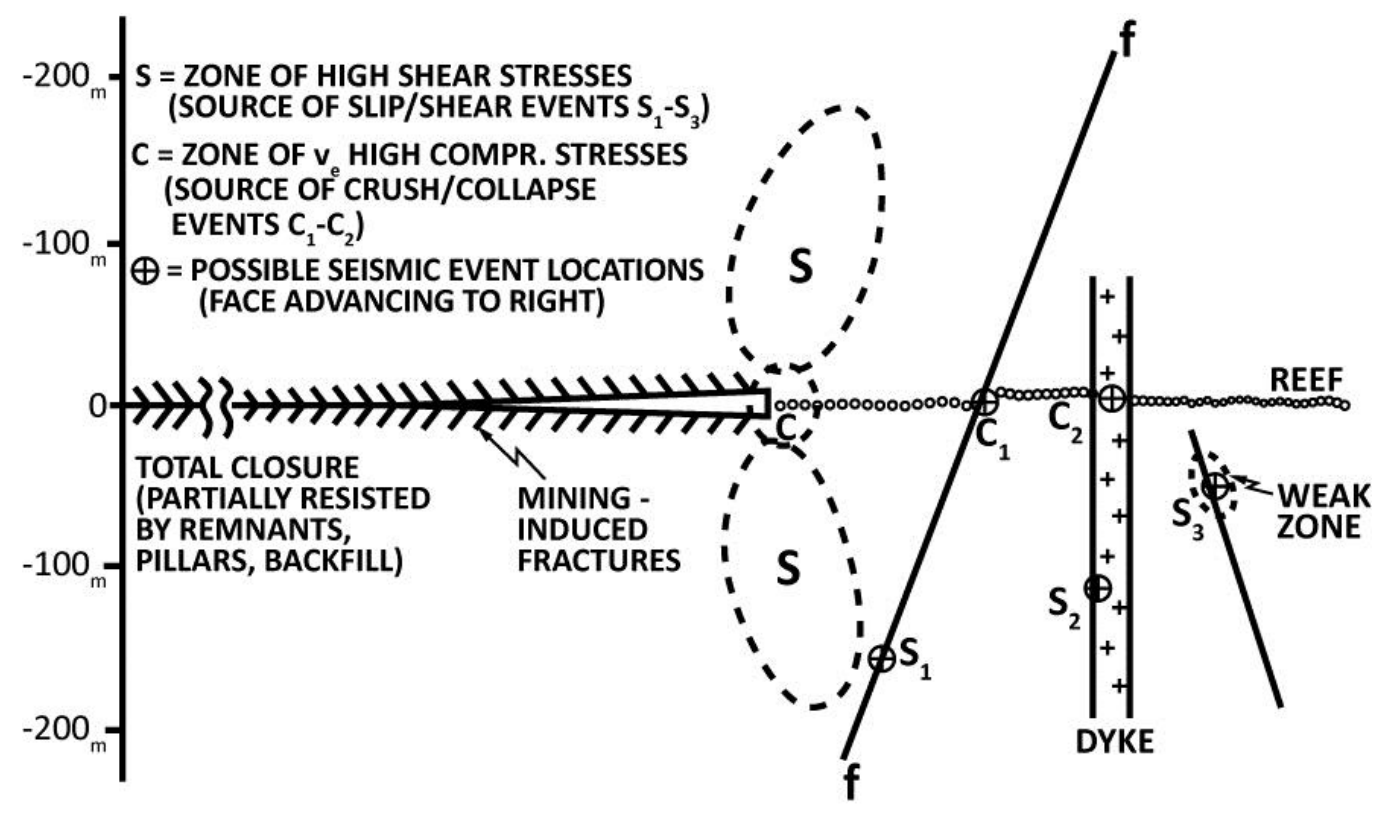

Figure 1 Shear (S) and compressive (C) stress conditions that generate the two generally accepted seismic source classes (Ryder, 1988)

\section{$2 \quad$ Assessing seismic response with the use of numerical modelling}

Different techniques have been developed to assess the seismic response of shear zones. Commonly used methods aim at assessing the extent of slippage on a fault plane as means to quantify the potential for seismicity. Some of these methods are the excess shear stress (ESS) method and the plastic ride estimation method.

ESS, introduced by Napier (1987) and Ryder (1987), has been applied to several case studies (Napier, 1987; Ryder, 1988; Spottiswoode, 1988; Webber, 1990; York and Dede, 1997). Using numerical modelling, this method calculates the shear stress exceeding the dynamic friction angle. The average ride can be calculated assuming a circular displacement dislocation (Salamon, 1964). With an estimate of ride, the seismic moment can then be calculated.

The disadvantages of this approach are the elastic assumptions on stress distribution that do not allow large rides, and the assumption of uniformity on the frictional dynamic strength that may over-predict the ride distribution (Board, 1994).

To overcome those disadvantages, explicit ride estimations were computed using the distinct element code (Board, 1994; Sjöberg et al., 2011) allowing stress redistribution around yielded zones, the explicit representation of shear zones, and plastic deformation on discontinuities.

The major drawbacks of this method are the strong dependence of the results on highly uncertain inputs such as faults and joint strengths, and joint distributions. Also, the time-consuming development and running of a 3D distinct element model combined with the low availability of such models at mine sites make this approach impractical for routine use.

Other methods used to calculate plastic shear slippage use ESS as a strength factor and boundary element models (BEM) with non-linear behaviour for plane surfaces (MAP3D; Wiles, 2011) to recreate plastic ride on faults. This gives considerably shorter run times, but again, the assessment of the ride is based on the strength properties input into the analysis (Hofmann and Sheepers, 2010).

It can be seen that one of the difficulties of the different methods to assess the seismic response of shear zones to mining has been the estimation of strength properties, which can lead to substantial changes in the simulated seismic response (Reimnitz, 2001). In this paper, a methodology partially independent of the strength properties based on the explicit simulation of the shear zone within a BEM is proposed. This 
methodology does not need strength properties as a priori, but it needs to be calibrated with real data in order to overcome the strength simplification. This methodology has been used in the past with favourable results to represent the seismic behaviour of faults at the El Teniente Mine (Jarufe, 2008; Potvin et al., 2010) and similar methods have been used to represent shear behaviour on contact zones (Orrego et al., 2010a).

\section{1 Method used in this paper}

\subsubsection{General overview}

To enable correlation between the seismic response of the shear zones and the shearing obtained from numerical modelling, each shear zone is represented by a displacement discontinuity plane (Wiles, 2011) with an average trend and plunge. The calculations that represent the shear movement of the whole zone will be conducted in this unique plane for each zone (Figure 2).

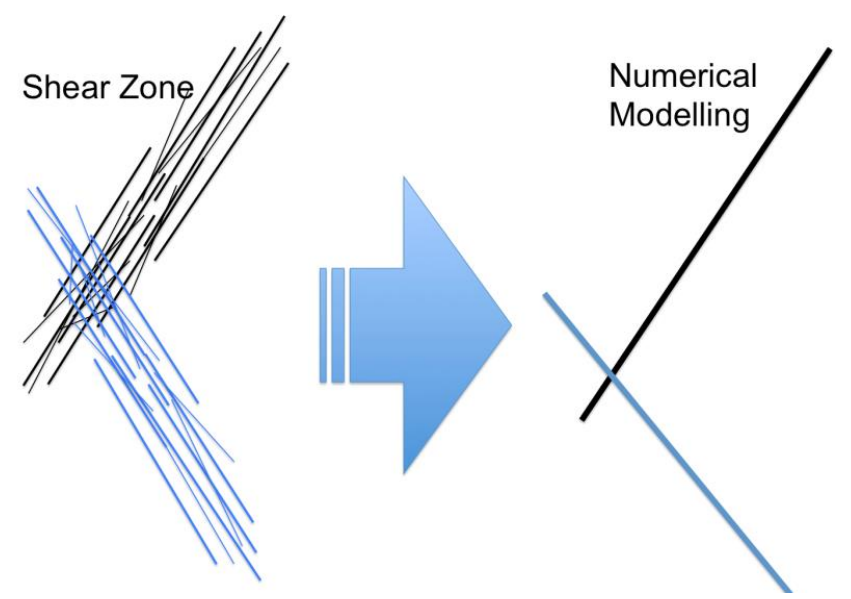

Figure 2 A shear zone (left) composed of series of faults and joints is represented as a non-linear displacement discontinuity plane ( $r$ ight) in the numerical modelling

Once the shear zones are simulated with planes, the conventional approach would be to assign strength properties for each of the planes. As each modelled plane represents one zone of shearing, potentially comprising fracture zones, discontinuities, gouge, etc., it is difficult to assess the strength parameters for the shear zone. To overcome this difficulty, the shear strength of the modelled surface was assumed to be at the LES during the pre-mining stage. The strength is therefore adjusted as to reach stability under the pre-mining shear and normal stress conditions acting on the plane (Figure 3). As a result, any subsequent increase in stress will trigger non-lineal displacements.

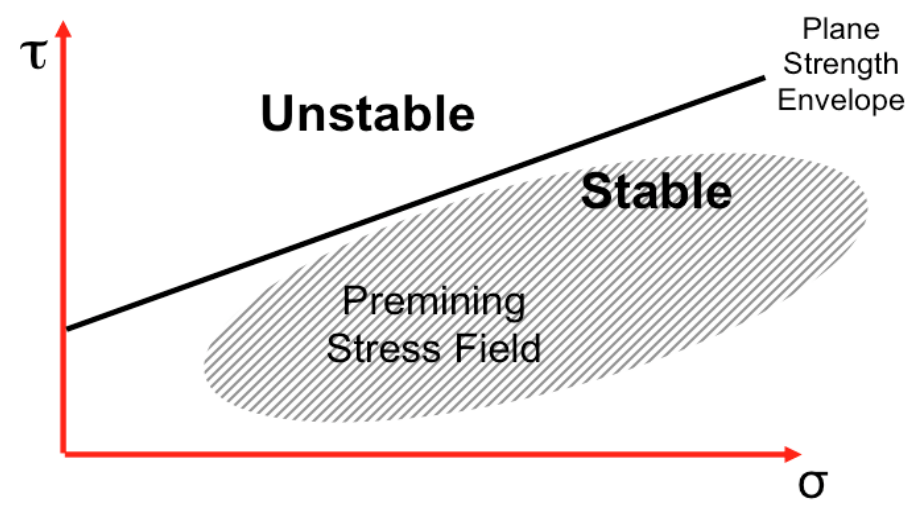

Figure 3 Schematic graph with the strength envelope just above the pre-mining stresses. Any increase in the stress field above the pre-mining values will undergo failure and nonlinear displacements (Jarufe, 2008) 
When mining starts and stress levels increase from the pre-mining state, non-linear strain occurs on the discretised elements of the modelled plane (Figure 4 top), and if one considers the area affected by movement and the non-linear strain on that area, a quantity proportional to the seismic moment can be calculated for each element. If this calculation is made for all elements on a mining step, a progression of the cumulative seismic moment can be simulated.

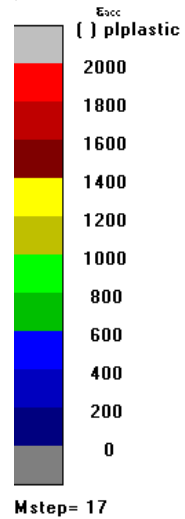

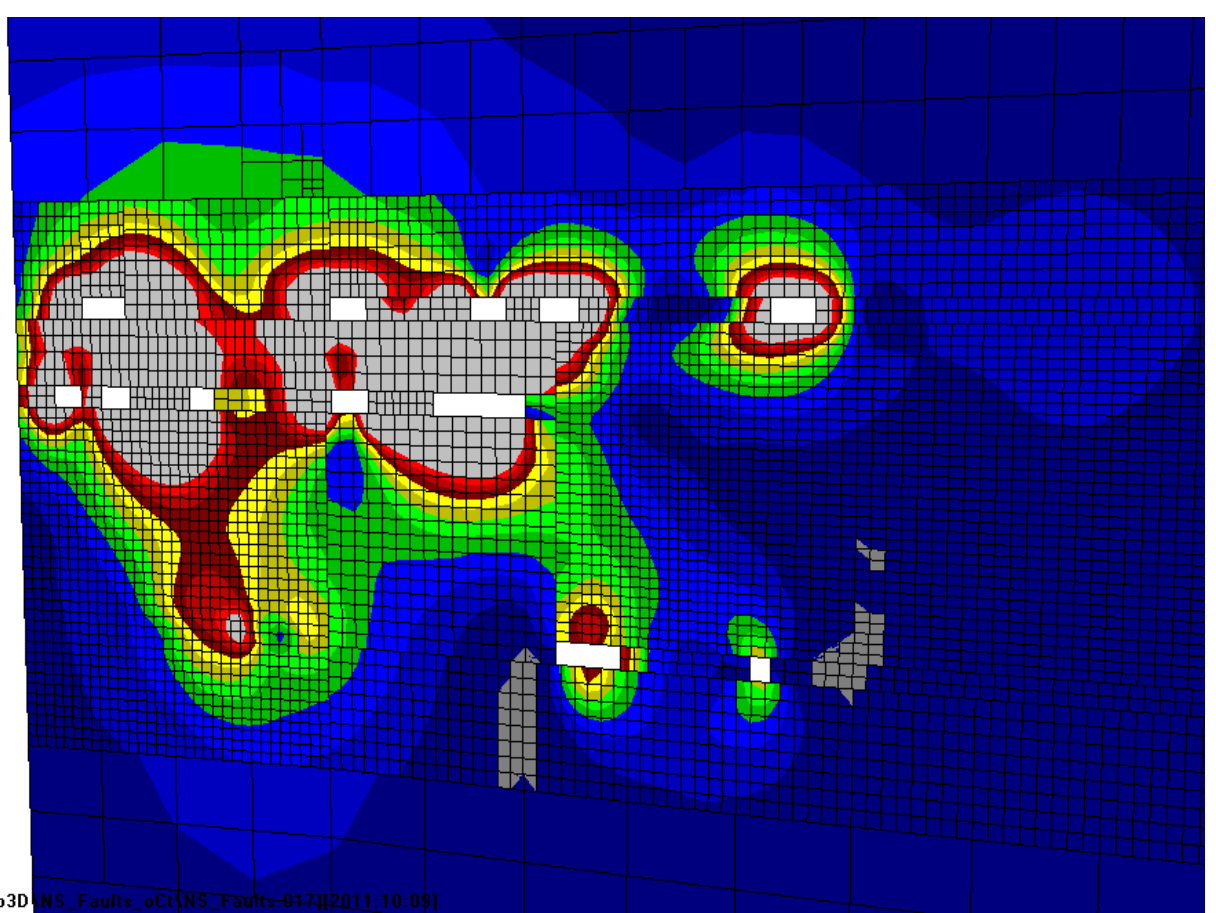

Numerical Model Results: Shear zone Id 15

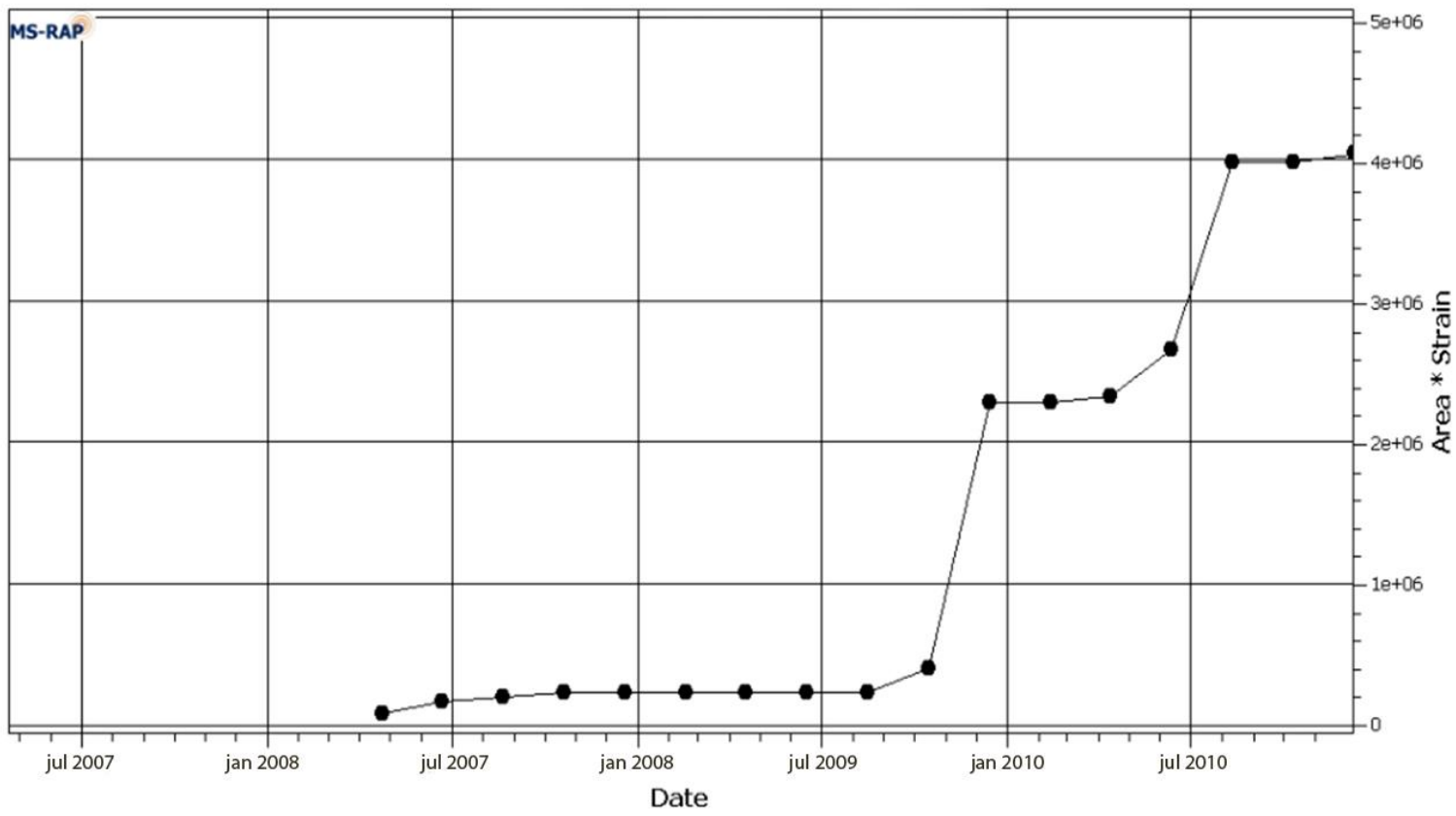

Figure 4 (Top) Discretisation of a displacement discontinuity plane with the plastic strain plotted. (Bottom) Simulated area * strain, proportional to the seismic moment

As such, the method does not aim to calculate the strength properties and directly predict the plastic ride, but should rather be seen as an assessment of the total potential for seismic slip and its relative spatial distribution, which is calibrated against seismic monitoring data obtained from previous mining response. 


\subsubsection{Calibration of the seismic slip potential}

The seismic slip potential is calibrated as follows: for each shear zone the seismic slip potential is defined in Equation (1) as follows:

$$
\begin{array}{cc}
\text { Modelled moment potential }=\mathrm{G} \sum_{\mathrm{i}}^{\mathrm{n}}\left(\varepsilon_{\mathrm{i}}-\varepsilon_{\mathrm{t}}\right) \cdot \mathrm{a} & \text { for } \varepsilon_{\mathrm{i}}>\varepsilon_{\mathrm{t}} \\
0 & \text { for } \varepsilon_{\mathrm{i}}<\varepsilon_{\mathrm{t}}
\end{array}
$$

where:

$$
\begin{array}{ll}
\varepsilon_{\mathrm{i}} & =\text { the calculated ride on each element. } \\
\varepsilon_{\mathrm{t}} & =\text { a threshold value of ride. }
\end{array}
$$

Seismic moment has been shown (Aki et al., 2002) to be equal to the product of the shear stiffness and the integration of the plastic ride over the area it is taking place.

The threshold value is estimated based on the observed zone of plastic displacement ahead of the mining face. Since previous analyses carried out at the mine site have shown that most of the seismicity occurs within $50 \mathrm{~m}$ of the mining face, the threshold value was adjusted so the non-linear displacement does not exceed this value. Then, each shear zone is weighted to reduce the error defined by Equation (2), which calculates the difference between 'measured' (obtained from seismic monitoring) and modelled values as a percentage of the measured value (Jarufe and Vasquez, 2008):

$$
\text { error }=\sqrt{\frac{\sum\left(\Delta \sigma_{\text {model-measured }}\right)^{2}}{\sum\left(\sigma_{\text {measured }}\right)^{2}}}
$$

\section{$3 \quad$ Case study}

\subsection{Background to mining environment}

The case study is based on a highly stressed panel caving mine exhibiting high seismicity rate and some large events. This panel caving mine progressively undercuts a thin layer of the rock mass (10 $\mathrm{m} \mathrm{high)} \mathrm{to}$ generate and propagate fractures upwards, breaking the rock mass and leaving it ready for bogging from the extraction level. The mine process starts with the drift development on several levels, then undercutting starts and later the bogging process commences from a deeper extraction level (Figure 5). As mining advances, these three processes are undertaken at the same time in different parts of the mine.

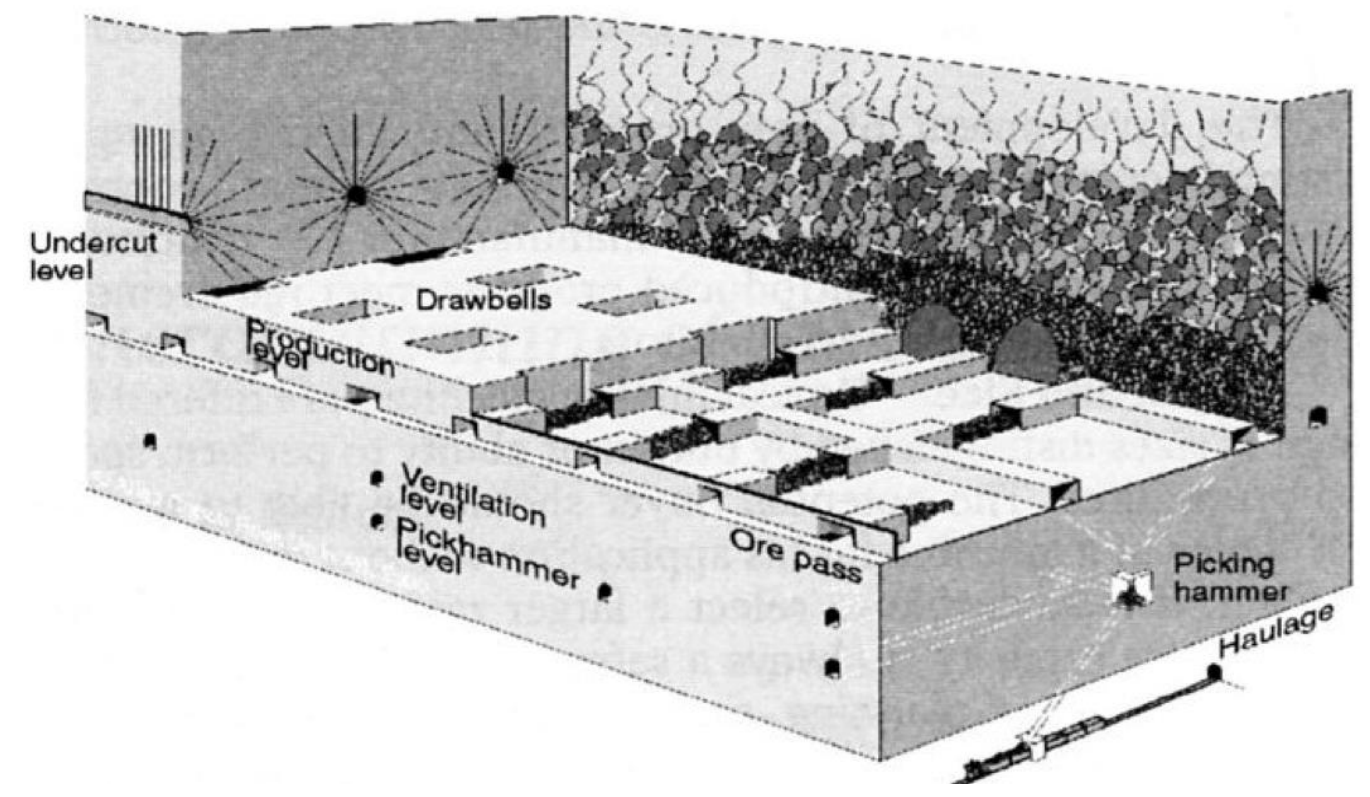

Figure 5 Conceptual diagram of the block caving method (Hustrulid and Bullock, 2001) 
The mine site under analysis is planned to produce 17,000 tpd during 2010 and started the development stage in early 2007. The undercutting commenced in August 2009 and production in June 2010 (Orrego et al., 2010a). Several large seismic events have occurred after undercutting started and before the beginning of production bogging (Orrego et al., 2010a). High levels of seismicity have continued thereafter.

For this mine sector, it is believed that not only are faults related to shear, but some lithology contacts as well. This is based on the ground control engineer's observations and is supported by moment tensor analysis performed on a large event (correctly picked up by the seismic system, with good location and source parameters) that occurred on the contact zone (Orrego et al., 2010b).

The geology of the zone is a porphyric/andesite host rock with several porphyric intrusions such as diorite, dacite, quartz, and anhydrite (Orrego et al., 2010a). These intrusions have irregular shapes (Figure 6) and are roughly vertical with strength and show a difference in elastic properties of approximately $20 \%$ compared to the host rock (Table 1).

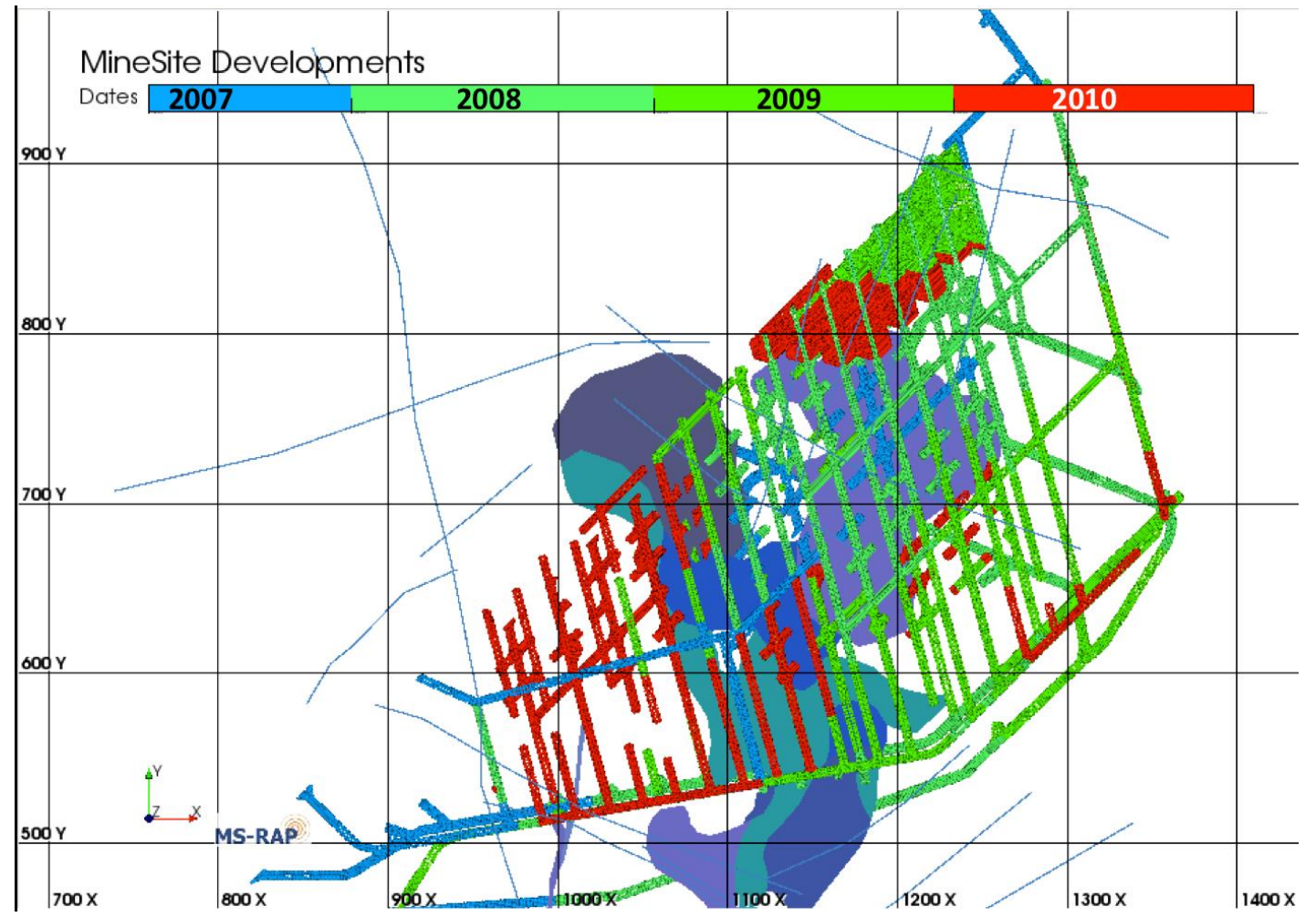

Figure $6 \mathrm{Plan}$ view of the mine layout coloured by mining stage, shear zones and different lithologies. This is the mine that is going to be analysed since early development to final production stage. The faults are shown with light blue lines

Table 1 Elastic and strength properties of some Iithologies at the mine site analysed (0rrego et al., 2010a)

\begin{tabular}{lccc}
\hline Property & $\begin{array}{c}\text { Andesite } \\
\text { (Host Rock) }\end{array}$ & $\begin{array}{c}\text { Andesitic } \\
\text { Porphyry }\end{array}$ & $\begin{array}{c}\text { Dioritic } \\
\text { Porphyry }\end{array}$ \\
\hline $\mathrm{E}(\mathrm{GPa})$ & 55 & 43 & 47 \\
Poisson & 0.25 & 0.25 & 0.25 \\
$\gamma\left(\right.$ ton $\left./ \mathrm{m}^{3}\right)$ & 2.84 & 2.74 & 2.71 \\
UCS $(\mathrm{MPa})$ & 121 & 123 & 144 \\
$\mathrm{C}(\mathrm{MPa})$ & 24 & 18 & 30 \\
$\Phi\left({ }^{\circ}\right)$ & 42 & 48 & 34 \\
\hline
\end{tabular}


Structural domains and major faults have similar geometric characteristics, with $\mathrm{N} 20^{\circ} \mathrm{E}$ and $\mathrm{N} 50^{\circ} \mathrm{W}$ trends and dipping subvertically (Orrego et al., 2010a). The geological settings and all mine developments through time can be seen on Figure 6.

\section{2 Seismic data}

A mine-wide seismic system was installed since the beginning of the development. The seismic system was designed to monitor mine scale seismicity (Dunlop and Rojas, 2001), with a $M_{\min }$ close to -1 . A combination of this sensitivity limit with the unfavourable geometrical distribution of the seismic sensors and the use of an automatic phase picking algorithm results in a generally high location error for the microseismicity generated through the development stage. Notwithstanding the source location inaccuracy, all events above $M_{L}=-1$ have a full waveform recorded and the quality of the source parameter generally appears to be acceptable.

For this analysis, it was assumed that all seismicity between $50 \mathrm{~m}$ above the undercut level (highest level) and $50 \mathrm{~m}$ below the ventilation level (deepest level) was triggered by development mining, undercutting or production, regardless of the location of the event. This is based on the high location error of seismic data (Jofre and Ortega, 2010).

Seismic moment and seismic energy are two parameters calculated directly from the average of the $S$ and $P$ waves (Gibowicz and Kijko, 1994) and can be used quantitatively to measure the seismic behaviour of the sector analysed. As seismic moment is similar to the area multiplied by the displacement calculated from numerical modelling, this parameter will be used to compare the model with real data.

\section{3 Results}

The model was calibrated with data from mid 2007 (development starting) to October 2009 (two months after undercutting started), and was used to predict seismic activity from October 2009 to December 2010. The comparison between real data and numerical model result is shown in Figure 7 . The error in the estimation for all data is approximately $31 \%$.

It can be seen that from August 2008 to July 2009 the numerical modelling trend is higher than the real seismicity (maintaining the trend). This could be due to the smallest events not being recorded by the seismic system during development. 


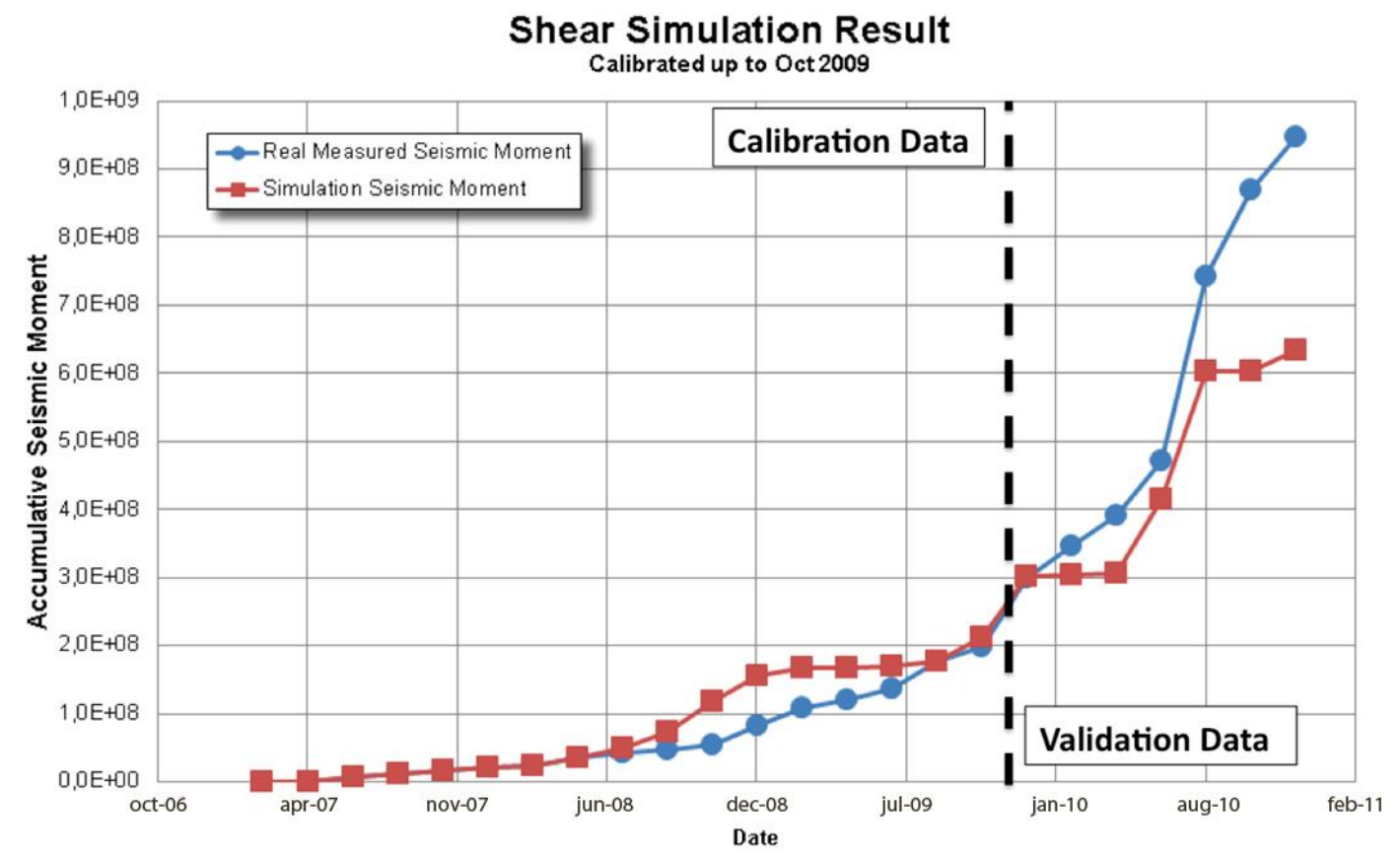

Figure 7 Comparison between the measured seismic moment on shear zones (blue line) and the modelled calibrated result (red line). The data used for calibration was taken from the start to October 2009

\section{4 Continuous calibration}

All numerical simulation methods require calibration before useful forecasting analysis can be performed. As new data becomes available, the model can continually be calibrated to improve the confidence in future assessments of potential seismicity. The process of continuous calibration was systematically evaluated. This was done by performing a calibration for each of the mining steps, starting at mining step 1 up to the last mining step. For each of these calibrated models, the forecast seismic moment potential was evaluated at each future mining step in order to assess the forecast potential of the model. The results are shown in Figure 8. Three different calibration periods were used.

It is important to note that the only development mining activity took place before August 2009 (no undercutting). Even when calibrating the model with development mining alone, good forecasts of the high seismic periods could be achieved. Also it is important to note that in this exercise, all geological features such as contacts and shear zones were known as priori and were always included in the model.

It is possible to see that as more information is taken into account in the calibration process, the difference between the measured and modelled value is reduced, thus reducing the error as calculated in Equation 2. When this error is plotted against the ratio of the calibration/forecasted period (Figure 9), it can be seen that to obtain an error in the forecasted magnitude of the seismic moment of less than $30 \%$, the calibration period must be at least seven times the forecasted period. Nevertheless, despite the high error in the magnitudes that can be obtained with small calibration periods, the global trends of modelled seismicity always reflect the observed seismic trends (Figure 8). 

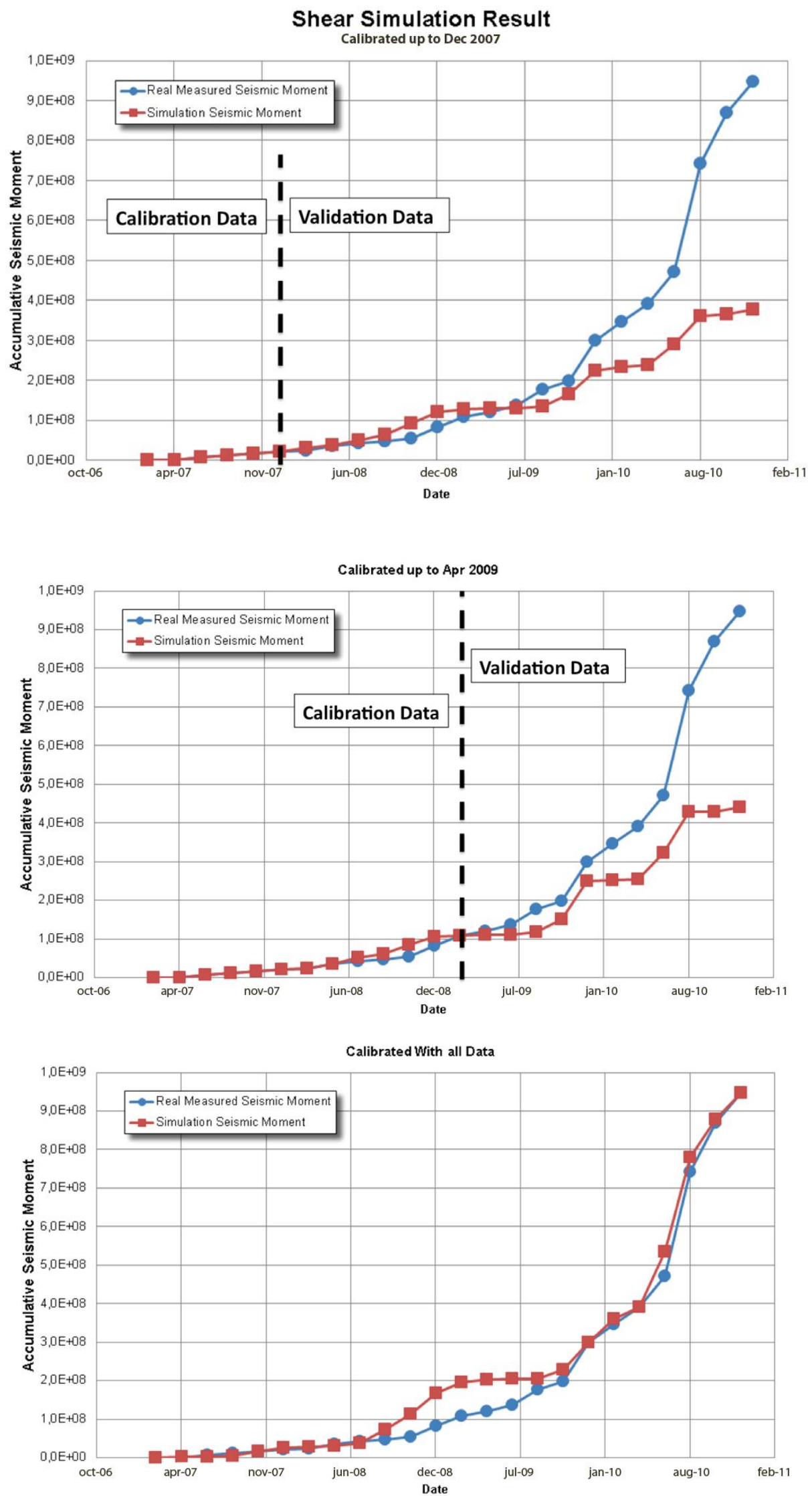

Figure 8 Comparison between the modelled and the measured data calibrating up to December 2007 (top), April 2009 (middle), and using the whole dataset to calibrate (bottom). Note that when few data is used to calibrate the model (top), the model forecast does not match the measured value very well, but the trend remains similar 


\section{Forecast error for different calibration/forecast ratios}

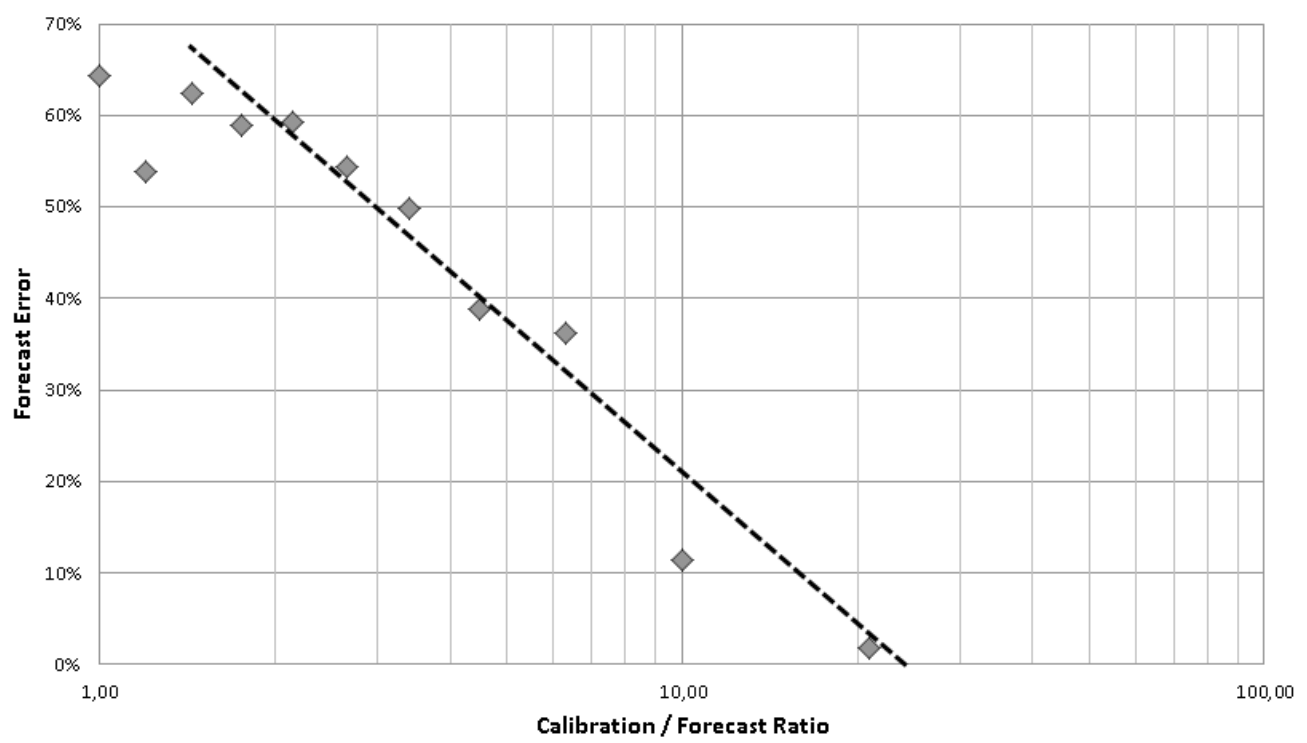

Figure 9 Modelled cumulative seismic moment error for different calibration/forecast periods

When numerical modelling is used with different calibration periods, the forecasted magnitude results will vary according to the error indicated in Figure 9. This means that the seismic moment forecasted value can vary between the error range (Figure 10). It is clear that the results change as more data is considered in the calibration process. It is also possible to see that even for low calibration-forecast ratios, the global trends on seismicity are correctly simulated, showing the major changes in the mine-induced seismicity.

The results demonstrate that to have errors below $30 \%$, significant calibration data is needed. One of the reasons for the high calibration requisite to achieve small errors may be related to the assumption that all seismicity is related to all shear zones. This assumption requires extra calibration stages to relate each group of seismic events to a particular shear zone. If the seismic network was more sensitive with high location accuracy, a reliable relation between events location and geological features producing shear seismicity could be established, and presumably fewer calibration steps would be needed.

Also it is important to note that once the calibration process is completed, the only variable in the results is the mining geometry and for all forecasted results, the error will be the same. This implies that the model can be used to compare different mine sequences and, considering they would have the same level of error, comparative studies can be performed reliably. 
Forecast Reliability

For different Forecast/Calibration ratios

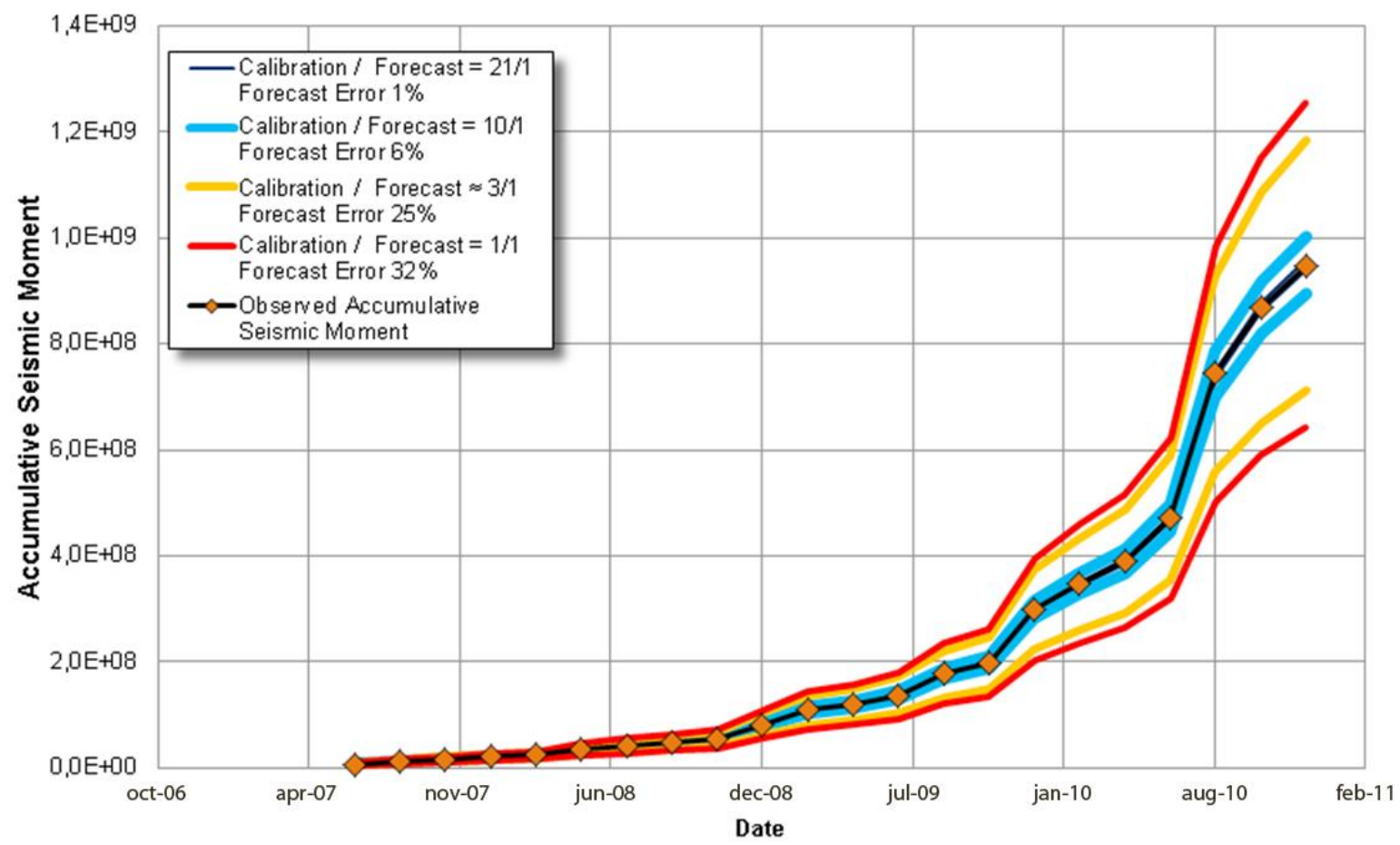

Figure 10 Three and a half year forecast (starting June 2007) with different levels of calibration/forecast ratios. As more data is considered in the calibration (and less in the forecast) the total error is reduced

\section{Conclusions}

In this paper, a brief review of the most relevant methods to assess the seismic response of shear zones showed that one of the major hurdles to numerically simulate this response is the definition of strength properties of shear zones since the simulation results are strongly dependent on these parameters. To overcome this difficulty, a method based on an extensive calibration but independent of the strength properties (LES) is applied and the error in model forecasts is calculated. In this case, the error is calculated as a difference between the measured and the modelled seismic moment (Equation 2). The result quantifies the expected error in modelling forecasting based on the amount of data used to calibrate the model. This error varies from $1 \%$, when large amounts of data is used to calibrate the model, to higher than $60 \%$, when the calibration period is similar to or less than the forecast period. Despite these large error values, the trends in the modelled and observed seismicity are always similar. The amounts of data used to calibrate the model may look exaggerated, but this is caused by some assumptions and simplifications particular to this case study. More precise seismic systems may allow a more focused analysis and a reduction of the calibration steps to get the desired expected error. Also, the method can be used as a tool to evaluate the seismic response of different mine sequences in terms of high and low seismicity periods with a known error in the magnitude of the estimation.

\section{Acknow ledgements}

The authors of this work thank Codelco Chile VP and The New Mine Level Project management, Jorge Revuelta and Eduardo Cordova, for authorising this work and their support. The authors also extend their thanks to Pablo Vasquez, NML geology and geotechnical manager and to the ACG team for their support. 


\section{References}

Board, M.P. (1994) Numerical Examination of mining induced seismicity, PhD Thesis, University of Minnesota.

Dunlop, R. and Rojas, E. (2001) Fundamentos para la conduccion de la respuesta sismica a un metodo de caving, El Teniente mine Internal Report № PL-I-202/2001.

Gibowicz, S.J. and Kijko, A. (1994) An Introduction to Mine Seismology, Academic Press, Inc., Nature, New York, 399 p.

Hofmann, G.F. and Sheepers, L.J. (2010) Simulating fault slip areas of mining induced seismic tremors using static boundary element numerical modelling, in Proceedings Fifth International Seminar on Deep and High Stress Mining (Deep Mining 2010), M. Van Sint Jan and Y. Potvin (eds), 6-8 October 2010, Santiago, Chile, Australian Centre for Geomechanics, Perth, pp. 395-412.

Hustrulid, W. and Bullock, L. (2001) Underground Mining Methods: Engineering fundamentals and international case studies, SME, ISBN 978-0873351935.

Jarufe, J. (2008) Avance estudio riesgo sismico Proyecto Nuevo Nivel Mina, Codelco Chile, New Mine Level Project, Internal project.

Jarufe, J. and Vasquez, P. (2008) Mine-Scale 3D Stress Model for the New Mine Level Project, El Teniente Mine, Codelco, Chile, in Proceedings First Southern Hemisphere International Rock Mechanics Symposium (SHIRMS), Y. Potvin, J. Carter, A. Dyskin and R. Jeffrey (eds), Vol. 1 - Mining and Civil, 16-19 September 2009, Perth, Australia, Australian Centre for Geomechanics, Perth, pp. 231-242.

Jofre, A. and Ortega, J. (2010) Evaluacion y control cuantitativo del riesgo sismico, Mathematical modelling Centre, University of Chile.

Napier, J.A.L. (1987) The application of excess shear stress to the design of mine layouts, Journal of the South African Institute of Mining and Metallurgy, Vol. 87, No. 12, pp. 397-405.

Orrego, C., Cuello, D. and Rojas, E. (2010a) Determination of induced stress condition inside Pilar Norte sector, in Proceedings Fifth International Seminar on Deep and High Stress Mining (Deep Mining 2010), M. Van Sint Jan and Y. Potvin (eds), 6-8 October 2010, Santiago, Chile, Australian Centre for Geomechanics, Perth, pp. 155-168.

Orrego, C., Parraguez, R. and Rojas, E. (2010b) Analisis causal de estallidos de rocas 17 de agosto 2010, mina Pilar Norte, Codelco Chile division El Teniente, Internal Report.

Ortlepp, W.D. (1997) Rock Fracture and Rockbursts, an illustrative study, Monograph Series M9, The South African Institute of Mining and Metallurgy, Johannesburg, South Africa.

Potvin, Y., Jarufe, J. and Wesseloo, J. (2010) Interpretation of seismic data and numerical modelling of fault reactivation at El Teniente Reservas Norte Sector (RENO), in Proceedings 2nd International Symposium on Block and Sublevel Caving (Caving 2010), Y. Potvin (ed), 20-22 April 2010, Perth, Australia, Australian Centre for Geomechanics, Perth, pp. 483-494.

Reimnitz, M. (2001) Homestake Mining Darlot Gold Mine Centenary Mine, Numerical Analysis Map3D, Mine Seismicity and Rockburst Risk Management Research project, Australian Centre for Geomechanics, Perth, Western Australia.

Ryder, J.A. (1987) Excess Shear Stress (ESS) An engineering criterion for assessing unstable slip and associated rockburst hazards, Journal of the South African Institute of Mining and Metallurgy, Vol. 88, No. 1, pp. 27-39.

Ryder, J.A. (1988) Excess shear stress in the assessment of geologically hazardous situations, Journal of the South African Institute of Mining and Metallurgy, Vol. 88, No. 1, pp. 27-39.

Salamon, M.D.G. (1964) Elastic analysis of displacements and stresses induced by the mining of seam or reef deposits Part II: Displacement, strain and stress, Journal of the South African Institute of Mining and Metallurgy, SAIMM, Vol. 64, No. 6, pp. 197-218.

Sjöberg, J., Dahnér, C., Malmgren, L. and Perman, F. (2011) Forensic Analysis of a Rock Burst event at the Kiirunavaara Mine Results and implications for the future, Continuum and Distinct Element Numerical Modeling in Geomechanics 2011, Itasca International Inc., Minneapolis, ISBN 978-0-976577-2-6.

Spottiswode, S.M. (1988) Total seismicity, and the application of ESS analysis to mine layouts, Journal of the South African Institute of Mining and Metallurgy, Vol. 88, No. 4, pp. 109-116.

Webber, S.J. (1990) Numerical modeling of a repeated fault slip, Journal of the South African Institute of Mining and Metallurgy, Vol. 90, No. 6, pp. 133-140.

Wiejacz, P. and Lugowski, A. (1997) Effects of Geological and Mining Structures upon Mechanism of Seismic Events at Wujek coal mine, Katowice, Poland, Rockburst and Seismicity in Mines, Balkema Publishers, ISBN 9054108908.

Wiles, T. (2011) Map3D user manual.

York, G. and Dede, T. (1997) Plane Strain Numerical Modelling of Mining Induced Seismicity through the Effects of Mine Geometry, Backfill and Dyke Material, on Tabular Reefs at great Depths, Rockburst and Seismicity in Mines, Balkema Publishers, ISBN 9054108908. 